\title{
PERANAN NET PRESENT VALUE (NPV) DAN INTERNAL RATE OF RETUR (IRR) DALAM KEPUTUSAN INVESTASI MESIN
} \author{
Decisions \\ Nunung Nurhayati ${ }^{1,}$ Ayu Diah Restiani ${ }^{2}$ \\ hajinunung86@gmail.com \\ Manajemen Fakultas Ekonomi Unwir
}

Present Value (NPV) And Internal Rate Of Return (IRR) Methode In Machines Investment

\begin{abstract}
ABSTRAK
Metode penelitian yang digunakan dalam penelitian ini adalah jenis penelitian berdasarkan tujuan penelitian yaitu metode asosiatif dan metode deskriptif, metode asosiatif yaitu penelitian yang menguji hubungan atau hubungan antara variabel, dua variabel atau lebih. Penelitian dilakukan pada CV. Seribu Wajah adalah perusahaan swasta yang bergerak dalam penyediaan jasa di bidang General Suplier dan Kontraktor. Berlokasi di Jalan Raya Tegalurung Ruko Balongan Pratama No.03-04 Balongan Indramayu. CV. Seribu Wajah berdiri pada tahun 2010 dalam bentuk Perseroan Komanditer (CV. Seribu Wajah).

Hasil penelitian menunjukkan bahwa peranan NPV memberikan pengaruh terhadap investasi mesin sebesar $32,70 \%$, sedangkan sisanya $67,30 \%$ dipengaruhi oleh faktor-faktor lain yang tidak diteliti. Sedangkan IRR memberikan pengaruh terhadap investasi mesin sebesar $100 \%$ atau memiliki pengaruh mutlak karena IRR merupakan indikator tingkat efisiensi dari suatu investasi. Artinya NPV dan IRR secara bersamasama berperan terhadap keputusan investasi mesin pada CV. Seribu Wajah.
\end{abstract}

Kata kunci: $N P V, I R R$, Investasi.

\begin{abstract}
The research method used in this study is the type of research based on the research objectives, namely associative methods and descriptive methods, associative methods, namely research that tests the relationship or relationship between variables, two variables or more. The study was conducted on CV. Seribu Wajah is a private company engaged in providing services in the General Supplier and Contractor fields. Located on Jalan Raya Tegalurung Ruko Balongan Pratama No.03-04 Balongan - Indramayu. CV. Seribu Wajah was established in 2010 in the form of a Regional Corporation (CV. Thousand Faces).

The results showed that the role of NPV had an influence on machine investment by $32.70 \%$, while the remaining $67.30 \%$ was influenced by other factors not examined. While IRR has an influence on machine investment by $100 \%$ or has an absolute
\end{abstract}

influence because IRR is an indicator of the level of efficiency of an investment. This means that NPV and IRR jointly contribute to the engine investment decisions on the $\mathrm{CV}$. Thousand Faces.

Keywords: NPV, IRR, Investment

\section{PENDAHULUAN}

Menilai layak atau tidaknya suatu investasi dapat ditinjau dari aspek pasar, teknis, keuangan, dan manajemen. Penelitian ini difokuskan pada aspek keuangan dalam mengambil suatu keputusan investasi dilakukan analisa keuangan pada aliran kas yang ditinjau dari pendapatan, pengeluaran dan pendanaan, pajak, cara pengembalian modal, pertumbuhan proyek tiap tahun. Berdasarkan hal tersebut maka metode Net Present Value dan Internal Rate of Return yang lebih rasional untuk digunakan dalam menentukan profitabilitas perusahaan karena memperhatikan time value of money.

CV. Seribu Wajah merupakan perusahaan yang bergerak di bidang jasa konstruksi, yang sebelumnya hanya mengandalkan kinerja dari manpower dalam mengerjakan proyek-proyek konstruksi yang dikerjakannya. Tentu saja hal tersebut berdampak pada produktifitas menjadi tidak efektif dan efisien. Mengingat hal tersebut, 
investasi aktiva tetap dalam bentuk pembelian mesin-mesin untuk menunjang operasional perusahaan perlu dilakukan. Untuk menilai keputusan investasi mesin yang dilakukan oleh CV. Seribu Wajah maka perlu dilakukan suatu analisis investasi yang tepatagar dapat meminimalkan resiko kerugian bagi perusahaan.

Rumusan Masalah

1. Bagaimana Net Present Value (NPV) pada CV. Seribu Wajah.

2. Bagaimana Internal Rate of Return (IRR) pada CV. Seribu Wajah.

3. Bagaimana Investasi Mesin pada CV. Seribu Wajah.

4. Bagaimana peranan Net Present Value (NPV) terhadap keputusan investasi mesin pada CV. Seribu Wajah.

5. Bagaimana peranan Internal Rate of Return (IRR) terhadap keputusan investasi mesin pada CV. Seribu Wajah.

6. Bagaimana peranan NPV dan IRR secara bersama-sama terhadap keputusan investasi mesin pada CV. Seribu Wajah.

Tujuan Penelitian

1. Untuk mengetahui Net Present Value (NPV) pada CV. Seribu Wajah.

2. Untuk mengetahui Internal Rate of Return (IRR) pada CV. Seribu Wajah.

3. Untuk mengetahui Investasi Mesin pada CV. Seribu Wajah
4. Untuk mengetahui peranan Net Present Value (NPV) terhadap keputusan investasi mesin pada CV. Seribu Wajah.

5. Untuk mengetahui peranan Internal Rate of Return (IRR) terhadap keputusan investasi mesin pada CV. Seribu Wajah.

6. Untuk mengetahui peranan NPV dan IRR secara bersama-sama terhadap investasi mesin pada CV. Seribu Wajah.

\section{TINJAUAN PUSTAKA}

Keputusan Investasi Mesin

Keputusan investasi mesin merupakan keputusan yang sangat menentukan keberhasilan perusahaan dan menyangkut pengalokasian dana yang berasal dari dalam maupun dari luar perusahaan dengan pilihan investasi dimasa akan datang.

Menurut Eduardus Tandelilin (2010:2) menyatakan investasi adalah:

"Komitmen atas sejumlah dana atau sumber daya lainnya yang dilakukan pada saat ini, dengan tujuan memperoleh sejumlah keuntungan di masa datang".

Menurut Sutrisno (2012:5) menyatakan bahwa keputusan investasi adalah:

"Masalah bagaimana manajer keuangan harus mengalokasikan dana ke dalam bentuk-bentuk investasi yang akan dapat mendatangkan keuntungan di masa yang akan datang”. 
Net Present Value (NPV)

Keputusan investasi ditinjau untuk mengetahui apakah investasi tersebut dikatakan layak atau tidak. Metode NPV menjadi metode yang paling umum digunakan oleh perusahaan. Pengertian net present value (NPV) merupakan metode yang mengukur profitibilitas rencana investasi mempergunakan faktor nilai waktu uang. Dengan cara membandingkan nilai sekarang dari aliran kas masuk bersih (proceeds) dengan nilai sekarang dari biaya pengeluaran suatu investasi (outlays).

Menurut R. Agus Sartono (2010:195) menyatakan bahwa :

"Net Present Value adalah Selisih antara present value aliran kas bersih atau sering disebut juga dengan procceed dengan present value Investasi”.

Menurut Suliyanto (2010:200) menyatakan bahwa:

"Metode Net Present Value merupakan metode yang dilakukan dengan cara membandingkan nilai sekarang dari aliran kas masuk bersih (proceeds) dengan nilai sekarang dari biaya pengeluaran suatu investasi (outlays)".

\section{Internal Rate of Return (IRR)}

Diperlukan suatu metode untuk menjelaskan apakah rencana investasi cukup menarik apabila dilihat dari segi tingkat pengembalian yang telah ditentukan, Prosedur yang lazim dipakai adalah mengkaji tingkat pengembalian internal rate of return (IRR) merupakan suatu metode yang digunakan untuk menghitung atau mencari tingkat bunga yang menjadikan jumlah nilai sekarang dari semua aliran kas masuk sama dengan aliran kas keluar dari suatu investasi.

Menurut Bambang Riyanto (2010:129) menyatakan bahwa:

"Pengertian internal rate of return itu sendiri dapat didefinisikan sebagai tingkat bunga yang akan menjadikan jumlah nilai sekarang dari proceeds yang diharapkan akan di terima (PV of future proceeds) sama dengan jumlah nilai sekarang dari pengeluaran modal (PV of capital outlays).”

Menurut Suliyanto (2010:211) Internal Rate of Return berpendapat bahwa:

"Metode yang digunkaan untuk menghitung tingkat bunga yang dapatmenyamakan antara nilai sekarang dari semua aliran kas masuk dengan aliran kaskeluar dari suatu investasi proyek".

Hubungan Antara Net Present Value Terhadap Investasi Mesin

Menghitung NPV diperlukan data tentang perkiraan biaya investasi, biaya operasi, dan pemeliharaan serta perkiraan manfaat/benefit dari proyek yang direncanakan. Metode NPV sangat disarankan kepada perusahaan sebagai alat untuk mengkaji keputusan investasi yang dilakukannya. Hal ini diharapkan agar keputusan pembelian 
mesin-mesin baru yang diambil sesuai dengan tujuan investasi tersebut yaitu memperoleh laba yang diharapkan.

Hubungan Antara Internal Rate of Return Terhadap Investasi Mesin

Menghitung IRR perusahaan harus terlebih dahulu mengetahui informasi mengenai investasi itu sendiri. Penerimaan atau penolakan usulan investasi ini adalah dengan membandingkan IRR dengan tingkat bunga yang disyaratkan (required rate of return). Apabila IRR lebih besar dari pada tingkat bunga yang disyaratkan maka proyek tersebut diterima, apabila lebih kecil diterima. Oleh karena itu metode IRR pada keputusan investasi sangat dibutuhkan menginat untuk menghindari resiko kegagalan dan terjadinya kerugian, perusahaan harus memperhitungkan dengan baik dengan metode yang tepat dan informasi mengenai usulan investasi yang tepat agar perusahaan mendapatkan manfaat dari investasi yang dilakukannya.

Hubungan Antara Net Present Value dan Internal Rate of Retrun Terhadap Investasi Mesin

Metode NPV dan IRR yang lebih rasional untuk digunakan dalam menentukan profitabilitas perusahaan karena memperhatikan time valueof money. Sebelum menentukan IRR, terlebih dahulu harus mencari hasil dari NPVdari proyek tersebut lalu dicoba dengan beberapa tingkatan discount rate sampai memperoleh positif dan negatif dimana mendekati dari hasil NPV proyek tersebut atau biasa disebut dengan cara trial and error.

\section{Kerangka Pemikiran}

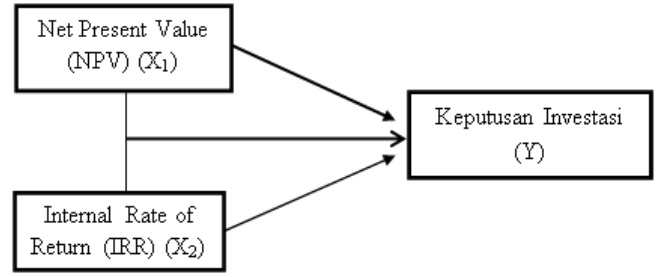

Gambar Kangka Pemikiran

\section{Hipotesis Penelitian}

1. Diduga terdapat pengaruh NPV terhadap keputusan investasi

2. Diduga terdapat pengaruh IRR terhadap keputusan investasi

3. Diduga terdapat pengaruh NPV dan IRR secara bersama-sama terhadap keputusan investasi

\section{METODE PENELITIAN}

Metode penelitian yang digunakan dalam penelitian ini adalah jenis penelitian berdasarkan tujuan penelitian yaitu metode asosiatif dan metode deskriptif, metode asosiatif yaitu penelitian yang menguji hubungan atau hubungan antara variabel, dua variabel atau lebih.

Menurut Sugiyono (2012: 13), menyatakan bahwa:

"Penelitian asosiatif merupakan penelitian yang bertujuan untuk mengetahui hubungan 
dua variabel atau lebih. Dalam penelitian ini akan dibangun suatu teori yang dapat berfungsi untuk menjelaskan, meramalkan, dan mengontrol suatu gejala”.

\section{Populasi dan Sampel}

Menurut Sugiyono (2012: 80) menyatakan bahwa populasi adalah wilayah generalisasi terdiri atas obyek/subyek yang mempunyai kualitas dan karakteristik tertentu. ditetapkan oleh peneliti untuk dipelajari dan kemudian ditarik kesimpulan.Populasi dalam penelitian ini adalah investasi mesin pada CV. Seribu Wajah sejak berdiri sampai tahun 2017.

Lebih lanjut menurut Sugiyono (2012: 81) sampel adalah sebagian dari jumlah dan karakteristik yang dimiliki oleh populasi tersebut. Sampel yang diambil dalam penelitian ini yaitu investasi mesin dari tahun 2016-2023.

\section{Teknik Pengumpulan Data}

1. Penelitian Kepustakaan

(Library

Research)

Penelitian kepustakaan merupakan penelitian yang dilakukan dengan cara memperoleh sumber dari literatur jurnal atau buku-buku ilmu pengetahuan yang ada kaitannya dengan masalah yang diteliti.

2. Penelitian Lapangan (Field Research) Penelitian lapangan merupakan penelitian yang dilakukan dengan cara melihat langsung kelapangan pada objek yang diteliti melalui wawancara dan observasi.

\section{Populasi dan Sampel}

Populasi dalam penelitian ini adalah investasi mesin pada CV. Seribu Wajah sejak berdiri sampai tahun 2017. Sedangkan sampel yang diambil dalam penelitian ini yaitu investasi mesin dari tahun 2016-2023.

\section{Operasionalisasi Variabel}

\begin{tabular}{|c|c|c|}
\hline Variabel & Indikator & $\begin{array}{c}\text { Skala } \\
\text { Pengukwran }\end{array}$ \\
\hline Investzsi (Y) & $\begin{array}{l}\text { 1. Dana Investasi Mesin } \\
\text { 2. Umur Mesin } \\
\text { 3. Metode Penyusutan }\end{array}$ & $\begin{array}{l}\text { Value / Nalai } \\
\text { Rasio } \\
\text { Rasio }\end{array}$ \\
\hline $\begin{array}{c}\text { hlat Presenf Value } \\
\text { (NPV) }\left(\mathrm{X}_{\mathrm{j}}\right)\end{array}$ & $\begin{array}{l}\text { 1. Suku Bunga } \\
\text { 2. Aliran Kas } \\
\text { 3. Periode Dilakukannya } \\
\text { Investasi } \\
\text { Bambang Riyanto (2010:12s) }\end{array}$ & $\begin{array}{c}\text { Ordinal } \\
\text { Value / Nilai } \\
\text { Rasio }\end{array}$ \\
\hline $\begin{array}{l}\text { Internat Rade of Refum } \\
\text { (IRR) (X) }\end{array}$ & $\begin{array}{l}\text { 1. Tingkat Bunga } \\
\text { 2. Cash Flow } \\
\text { Bambang Riyanto (2010:131) }\end{array}$ & $\begin{array}{l}\text { Ordinal } \\
\text { Rasio }\end{array}$ \\
\hline
\end{tabular}

Tabel 1. Operasional Variabel

\section{HASIL DAN PEMBAHASAN}

\section{Investasi mesin CV. Seribu Wajah}

Investasi mesin yang dilakukan $\mathrm{CV}$. Seribu Wajah yaitu dengan pembelian mesin baru berupa Wheel Loader Pada tahun 2016 yang bertujuan untuk mempermudah kegiatan operasional agar lebih efektif dan efisien. Berdasarkan laporan neraca perusahaan pada tahun 2016 CV. Seribu Wajah melakukan pembelian 2 mesin yaitu mesin wheel loader dan motor grader karena keterbatasan waktu peneliti hanya menganalisis satu mesin yaitu wheel loader diketahui nilai investasi yang dikeluarkan 
sebesar Rp. 500.000.000. dengan sumber biaya terdiri dari $85 \%$ modal sendiri dan $15 \%$ modal asing, dan masa manfaat diperkitakan selama 8 tahun dan diketahui nilai sisa alat sebesar $10 \%$ dari harga alat yaitu Rp.50.000.000 sehingga di peroleh depresiasi mesin tersebut sebesar Rp.56.250.000.

Proyeksi Investasi Mesin Selama 8 Tahun

\begin{tabular}{|c|c|c|c|}
\hline $\begin{array}{c}\text { Tahu } \\
\mathrm{n}\end{array}$ & $\begin{array}{c}\text { Investasi } \\
\text { Mesin }\end{array}$ & Depresiasi & Jumlah \\
\hline 2016 & $\begin{array}{c}500.000 .00 \\
0\end{array}$ & $\begin{array}{c}56.250 .00 \\
0\end{array}$ & $\begin{array}{c}443.750 .00 \\
0\end{array}$ \\
\hline 2017 & $\begin{array}{c}443.750 .00 \\
0\end{array}$ & $\begin{array}{c}56.250 .00 \\
0\end{array}$ & $\begin{array}{c}387.500 .00 \\
0\end{array}$ \\
\hline 2018 & $\begin{array}{c}387.500 .00 \\
0\end{array}$ & $\begin{array}{c}56.250 .00 \\
0\end{array}$ & $\begin{array}{c}331.250 .00 \\
0\end{array}$ \\
\hline 2019 & $\begin{array}{c}331.250 .00 \\
0\end{array}$ & $\begin{array}{c}56.250 .00 \\
0\end{array}$ & $\begin{array}{c}275.000 .00 \\
0\end{array}$ \\
\hline 2020 & $\begin{array}{c}275.000 .00 \\
0\end{array}$ & $\begin{array}{c}56.250 .00 \\
0\end{array}$ & $\begin{array}{c}218.750 .00 \\
0\end{array}$ \\
\hline 2021 & $\begin{array}{c}218.750 .00 \\
0\end{array}$ & $\begin{array}{c}56.250 .00 \\
0\end{array}$ & $\begin{array}{c}162.500 .00 \\
0\end{array}$ \\
\hline 2022 & $\begin{array}{c}162.500 .00 \\
0\end{array}$ & $\begin{array}{c}56.250 .00 \\
0\end{array}$ & $\begin{array}{c}106.250 .00 \\
0\end{array}$ \\
\hline 2023 & $\begin{array}{c}106.250 .00 \\
0\end{array}$ & $\begin{array}{c}56.250 .00 \\
0\end{array}$ & 50.000 .000 \\
\hline
\end{tabular}

Sumber: Data Primer yang Telah diolah Perhitungan Biaya Modal (Cost of Capital)

Dari data yang diperoleh dapat diketahui sebagai berikut:

- Presentase biaya modal sendiri: $85 \%$

- Presentase biaya modal asing: $15 \%$

- Besar Tarif Pajak: 10\%

Sehingga perhitungan biaya modal sebagai berikut:

Biaya modal $(\mathrm{CoC})=$ biaya hutang $\mathrm{x}(1$ pajak)

$$
\begin{aligned}
& =15 \% \times(1-10 \%) \\
& =15 \% \times(1-0,1)=13,5 \%
\end{aligned}
$$

Perhitungan Forecasting EAT

Dengan menggunakan metode forecasting time series analysis yaitu analisis trend melalui program POM for Windows versi 3.0 didapat peramalan EAT sebagai berikut:

Proyeksi Laba Bersih Sesudah Pajak Tahun 2018-2023

\begin{tabular}{|c|c|}
\hline Tahun & EAT (Rupiah) \\
\hline 2018 & 139.472 .700 \\
\hline 2019 & 143.366 .900 \\
\hline 2020 & 147.261 .000 \\
\hline 2021 & 151.155 .200 \\
\hline 2022 & 155.049 .300 \\
\hline 2023 & 158.943 .500 \\
\hline
\end{tabular}

Perhitungan Cash Flow Investasi

\begin{tabular}{|c|c|c|c|c|c|}
\hline Tahum & EAT & Depresiasi & $\mathbf{i}(\mathbf{l}-\mathbf{t})$ & $\begin{array}{c}\text { Terminal } \\
\text { CF }\end{array}$ & Cash Flow \\
\hline 2016 & 136911.000 & 56.250 .000 & 12.150 .000 & & 205.311 .000 \\
\hline 2017 & 142.794900 & 56.250 .000 & 12.150 .000 & & 211.194900 \\
\hline 2018 & 139.472 .700 & 56.250 .000 & 12.150 .000 & & 207.872 .700 \\
\hline 2019 & 143.366900 & 56.250 .000 & 12.150 .000 & & 211.366900 \\
\hline 2020 & 147.261 .000 & 56.250 .000 & 12.150 .000 & & 215.661 .000 \\
\hline 2021 & 151.155 .200 & 56.250 .000 & 12.150 .000 & & 219555.200 \\
\hline 2022 & 155.049 .300 & 56.250 .000 & 12.150 .000 & & 223.449 .300 \\
\hline 2023 & 158943500 & 56.250 .000 & 12.150 .000 & 50.000 .000 & 277.343500 \\
\hline
\end{tabular}

Sumber: data primer yang telah diolah Perhitungan Net Present Value (NPV)

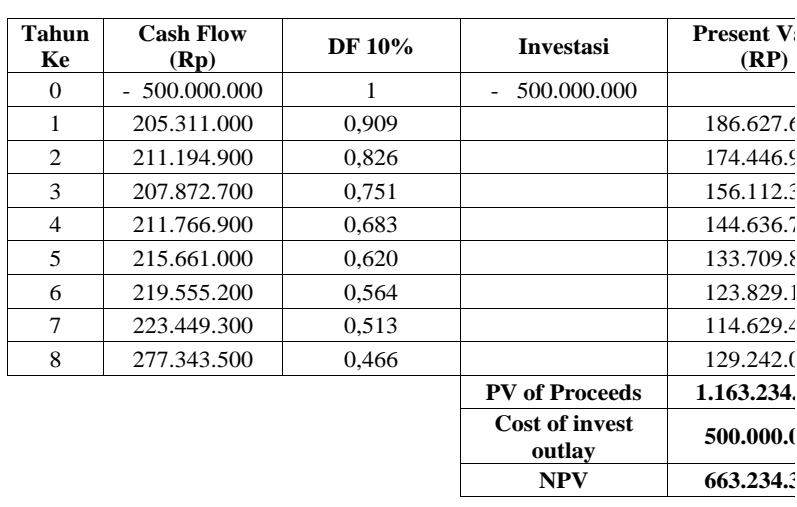


Perhitungan Internal Rate of Return (IRR)

\begin{tabular}{|c|c|c|c|c|}
\hline $\begin{array}{c}\text { Tahun } \\
\text { Ke }\end{array}$ & $\begin{array}{c}\text { Cash Flow } \\
(\text { Rp) }\end{array}$ & DF 40\% & Investasi & $\begin{array}{r}\text { Present V } \\
(\mathbf{R P})\end{array}$ \\
\hline 0 & -500.000 .000 & 1 & -500.000 .000 & \\
\hline 1 & 205.311 .000 & 0,714 & & 146.592 .1 \\
\hline 2 & 211.194 .900 & 0,510 & & $107.709 .$. \\
\hline 3 & 207.872 .700 & 0,364 & & 75.665 .6 \\
\hline 4 & 211.766 .900 & 0,260 & & 55.059 .3 \\
\hline 5 & 215.661 .000 & 0,185 & & 39.897 .2 \\
\hline 6 & 219.555 .200 & 0,132 & & 28.981 .2 \\
\hline 7 & 223.449 .300 & 0,094 & & 21.004 .2 \\
\hline 8 & 277.343 .500 & 0,067 & & 18.582 .0 \\
\hline & & & PV of Proceeds & $\mathbf{4 9 3 . 4 9 1 . .}$ \\
\cline { 4 - 5 } & & & $\begin{array}{c}\text { Cost of invest } \\
\text { outlay }\end{array}$ & $\mathbf{5 0 0 . 0 0 0 . 1}$ \\
\cline { 4 - 5 } & & & NPV & $-\mathbf{6 . 5 0 8 . 6}$ \\
\cline { 4 - 5 } & & &
\end{tabular}

\section{Analisis Deskriptif}

\begin{tabular}{|c|c|c|c|}
\hline Periode & Investasi Mesin & NPV & IRR \\
\hline 2016 & 443.750 .000 & 186.627 .699 & 146.592 .054 \\
\hline 2017 & 387.500 .000 & 174.446 .987 & 107.709 .399 \\
\hline 2018 & 331.250 .000 & 156.112 .398 & 75.665 .663 \\
\hline 2019 & 275.000 .000 & 144.636 .793 & 55.059 .394 \\
\hline 2020 & 218.750 .000 & 133.709 .820 & 39.897 .285 \\
\hline 2021 & 162.500 .000 & 123.829 .133 & 28.981 .286 \\
\hline 2022 & 106.250 .000 & 114.629 .491 & 21.004 .234 \\
\hline 2023 & 50.000 .000 & 129.242 .071 & 18.582 .015 \\
\hline$\sum$ & 1.975 .000 .000 & 1.163 .234 .392 & 493.491 .330 \\
\hline Rata - rata & $\mathbf{2 4 6 . 8 7 5 . 0 0 0}$ & $\mathbf{1 4 5 . 4 0 4 . 2 9 9}$ & $\mathbf{6 1 . 6 8 6 . 4 1 6}$ \\
\hline
\end{tabular}

Analisis Korelasi Net Present Value Terhadap Investasi Mesin

Untuk mengetahui korelasi antara variabel NPV dan variabel investasi mesin dengan menggunakan rumus korelasi rank spearman karena data yang berdistribusi tidak normal, berikut perhitungan korelasinya:

Tabel Penolong Korelasi NPV $\left(\mathrm{X}_{1}\right)$ terhadap Investasi Mesin (Y)

\begin{tabular}{|c|c|c|c|c|c|c|}
\hline $\mathbf{N}$ & $\mathbf{X} \mathbf{1}$ & $\mathbf{Y}$ & $\mathbf{R x}$ & $\mathbf{r y}$ & $\mathbf{b i}$ & $\mathbf{b i}^{\mathbf{2}}$ \\
\hline 1 & 186.627 .699 & 443.750 .000 & 1 & 1 & 0 & 0 \\
\hline 2 & 174.446 .987 & 387.500 .000 & 2 & 2 & 0 & 0 \\
\hline 3 & 156.112 .398 & 331.250 .000 & 3 & 3 & 0 & 0 \\
\hline 4 & 144.636 .793 & 275.000 .000 & 4 & 4 & 0 & 0 \\
\hline 5 & 133.709 .820 & 218.750 .000 & 5 & 5 & 0 & 0 \\
\hline 6 & 123.829 .133 & 162.500 .000 & 7 & 6 & 1 & 1 \\
\hline 7 & 114.629 .491 & 106.250 .000 & 8 & 7 & 1 & 1 \\
\hline 8 & 129.242 .071 & 50.000 .000 & 6 & 8 & -2 & 4 \\
\hline & \multicolumn{7}{|c}{ Jumlah } & $\mathbf{0}$ & $\mathbf{6}$ \\
\hline
\end{tabular}

Nunung Nurhayati dan Ayu Diah Restiani

Berdasarkan perhitungan pada tabel diatas maka nilai koefisien korelasi (r) dapat dihitung sebagai berikut:

$$
\begin{aligned}
& \rho=1-\frac{6 \sum b i^{2}}{n\left(n^{2}-1\right)} \\
& \rho=1-\frac{6 \sum 6^{2}}{8\left(8^{2}-1\right)} \\
& \rho=0,572
\end{aligned}
$$

Dari hasil perhitungan diatas diperoleh nilai koefisien korelasi (r) adalah 0,572 yang berarti korelasi sedang dan positif, maka korelasi antara variabel $\mathrm{X}_{1}(\mathrm{NPV})$ dan variabel Y (investasi mesin) searah. Dengan kata lain, kenaikan atau penurunan variabel $\mathrm{X}_{1}$ (NPV) terjadi secara bersama-sama dengan kenaikan atau penurunan variabel $\mathrm{Y}$ (investasi mesin).

Analisis Korelasi Internal Rate of Return Terhadap Investasi Mesin

\begin{tabular}{|c|c|c|c|c|c|c|}
\hline $\mathbf{N}$ & $\mathbf{X}_{\mathbf{2}}$ & $\mathbf{Y}$ & $\mathbf{R x}$ & $\mathbf{r y}$ & $\mathbf{b i}$ & $\mathbf{b i}^{\mathbf{2}}$ \\
\hline 1 & 146.592 .054 & 443.750 .000 & 1 & 1 & 0 & 0 \\
\hline 2 & 107.709 .399 & 387.500 .000 & 2 & 2 & 0 & 0 \\
\hline 3 & 75.665 .663 & 331.250 .000 & 3 & 3 & 0 & 0 \\
\hline 4 & 55.059 .394 & 275.000 .000 & 4 & 4 & 0 & 0 \\
\hline 5 & 39.897 .285 & 218.750 .000 & 5 & 5 & 0 & 0 \\
\hline 6 & 28.981 .286 & 162.500 .000 & 6 & 6 & 0 & 0 \\
\hline 7 & 21.004 .234 & 106.250 .000 & 7 & 7 & 0 & 0 \\
\hline 8 & 18.582 .015 & 50.000 .000 & 8 & 8 & 0 & 0 \\
\hline
\end{tabular}

Berdasarkan perhitungan pada tabel diatas maka nilai koefisien korelasi (r) dapat dihitung sebagai berikut:

$$
\begin{aligned}
& \rho=1-\frac{6 \sum b i^{2}}{n\left(n^{2}-1\right)} \\
& \rho=1-\frac{6 \sum 0^{2}}{8\left(8^{2}-1\right)} \\
& \rho=1,000
\end{aligned}
$$


Dari hasil perhitungan diatas diperoleh nilai koefisien korelasi (r) adalah 1,000 yang berarti korelasi yang sangat kuat dan positif, maka korelasi antara variabel $\mathrm{X}_{2}$ (IRR) dan variabel Y (investasi mesin) searah. Dengan kata lain, kenaikan atau penurunan variabel $\mathrm{X}_{2}$ (IRR) terjadi secara bersama-sama dengan kenaikan atau penurunan variabel $\mathrm{Y}$ (investasi mesin).

Analisis Korelasi Net Present Value Terhadap Internal Rate of Return

\begin{tabular}{|c|c|c|c|c|c|c|}
\hline $\mathbf{N}$ & $\mathbf{X}_{\mathbf{1}}$ & $\mathbf{X}_{\mathbf{2}}$ & $\mathbf{r x} \mathbf{1}$ & $\mathbf{r x} \mathbf{2}$ & $\mathbf{b i}$ & $\mathbf{b i}^{2}$ \\
\hline 1 & 186.627 .699 & 146.592 .054 & 1 & 1 & 0 & 0 \\
\hline 2 & 174.446 .987 & 107.709 .399 & 2 & 2 & 0 & 0 \\
\hline 3 & 156.112 .398 & 75.665 .663 & 3 & 3 & 0 & 0 \\
\hline 4 & 144.636 .793 & 55.059 .394 & 4 & 4 & 0 & 0 \\
\hline 5 & 133.709 .820 & 39.897 .285 & 5 & 5 & 0 & 0 \\
\hline 6 & 123.829 .133 & 28.981 .286 & 7 & 6 & 1 & 1 \\
\hline 7 & 114.629 .491 & 21.004 .234 & 8 & 7 & 1 & 1 \\
\hline 8 & 129.242 .071 & 18.582 .015 & 6 & 8 & -2 & 4 \\
\hline & \multicolumn{7}{|c}{ Jumlah } & $\mathbf{0}$ & $\mathbf{6}$ \\
\hline
\end{tabular}

Berdasarkan perhitungan pada tabel diatas maka nilai koefisien korelasi (r) dapat dihitung sebagai berikut:

$$
\begin{aligned}
& \rho=1-\frac{6 \sum b i^{2}}{n\left(n^{2}-1\right)} \\
& \rho=1-\frac{6 \sum 6^{2}}{8\left(8^{2}-1\right)} \\
& \rho=1-0,428 \\
& \rho=0,572
\end{aligned}
$$

Dari hasil perhitungan diatas diperoleh nilai koefisien korelasi (r) adalah 0,572 yang berarti korelasi yang sedang dan positif, maka korelasi antara variabel $\mathrm{X}_{1}(\mathrm{NPV})$ dan variabel $\mathrm{X}_{2}$ (IRR) searah. Dengan kata lain, kenaikan atau penurunan variabel $\mathrm{X}_{1}(\mathrm{NPV})$ terjadi secara bersama-sama dengan kenaikan atau penurunan variabel $\mathrm{X}_{2}$ (IRR).

Analisis Koefisien Determinasi

Analisis Koefisien Determinasi NPV terhadap keputusan investasi

Untuk mengetahui seberapa besar kontribusi yang diberikan NPV terhadap investasi mesin, maka digunakan rumus koefisien determinsi sebagai berikut:

$\mathrm{Kd}=\mathrm{r}^{2} \times 100 \%$

$\mathrm{Kd}=0,572^{2} \times 100 \%$

$\mathrm{Kd}=0,327 \times 100 \%$

$\mathrm{Kd}=32,70 \%$

Artinya NPV memberikan pengaruh terhadap investasi mesin sebesar $32,70 \%$, sedangkan sisanya $67,30 \%$ dipengaruhi oleh faktor-faktor lain yang tidak diteliti.

Analisis Koefisien Determinasi IRR terhadap keputusan investasi

Untuk mengetahui seberapa besar kontribusi yang diberikan

IRR terhadap investasi mesin, maka digunakan rumus koefisien determinsi sebagai berikut:

$$
\begin{aligned}
\mathrm{Kd} & =\mathrm{r}^{2} \times 100 \% \\
\mathrm{Kd} & =1^{2} \times 100 \% \\
\mathrm{Kd} & =1 \times 100 \% \\
\mathrm{Kd} & =100 \%
\end{aligned}
$$

Artinya IRR memberikan pengaruh terhadap investasi mesin sebesar $100 \%$ atau memiliki pengaruh mutlak karena IRR merupakan indikator tingkat efisiensi dari suatu investasi. 


\section{Kesimpulan}

1. Perhitungan NPV digunakan untuk menentukan kelayakan investasi mesin yang dilakukan CV. Seribu Wajah. Investasi dikatakan layak apabila PV arus keluar < PV arus kas masuk. Hasil penelitian yang dilakukan bahwa nilai investasi (PV arus kas keluar) adalah Rp. 500.000.000,00 sedangkan PV arus kas masuk sebesar Rp. 1.163.234.392,00 sehingga diperoleh nilai NPV sebesar Rp. 663.234.392.,00, sehingga keputusan investasi mesin yang dilakukan oleh CV. Seribu Wajah dianggap layak untuk dilakukan.

2. Berdasarkan hasil perhitungan IRR diperoleh sejumlah $39,71 \%$. Nilai IRR ini lebih tinggi dari pada nilai cost of capital perusahaan yaitu sebesar 13,5\%. Dengan demikan, kriteria internal rate of return investasi tersebut dapat diterima.

3. Berdasarkan hasil penelitian diketahui pada tahun 2016 CV. Seribu Wajah melakukan pembelian 2 mesin yaitu mesin wheel loader dan motor grader karena keterbatasan waktu peneliti hanya menganalisis satu mesin yaitu wheel loader diketahui nilai investasi yang dikeluarkan sebesar Rp. 500.000.000. dengan sumber biaya terdiri dari $85 \%$ modal sendiri dan $15 \%$ modal asing.

4. Peranan NPV pada penelitian ini adalah sebagai alat untuk menentukan layak atau tidaknya keputusan investasi mesin pada CV. Seribu Wajah, dan hasil dari perhitungan NPV yang telah dilakukan maka dapat diketahui keputusan investasi mesin tersebut layak untuk dilakukan karena memenuhi kriteria NPV > 0, maka usulan investasi dilaksanakan. Secara perhitungan statistik menggunakan korelasi rank spearman diperoleh koefisien korelasi (r) adalah 0,572 yang berarti korelasi sedang dan positif. Koefisien determinasi $\mathrm{Kd}=32,70 \%$ yang berarti NPV memberikan pengaruh terhadap investasi mesin sebesar 32,70\% , sedangkan sisanya 67,30\% dipengaruhi oleh faktor-faktor lain yang tidak diteliti.

5. Peran IRR dalam penelitian ini sebagai indikator tingkat efisiensi suatu investasi dapat diterima atau tidak. Dari hasil penelitian diperoleh nilai IRR lebih besar dari nilai cost of capital perusahaan tersebut sehingga keputusan investasi mesin pada CV. Seribu Wajah layak untuk dilakukan. Nilai tersebut diperoleh dari perhitungan dengan metode trial erroe sampai didapatkan nilai IRR yang menggambarkan tingkat imbalan yang diterima perusahaan dari investasi mesin yang dilakukannya. Secara perhitungan statistik menggunakan korelasi rank spearman diperoleh koefisien korelasi (r) adalah 1,000 yang berarti korelasi sengat kuat dan positif. Koefisien determinasi $\mathrm{Kd}=100 \%$ yang berarti IRR 
memberikan pengaruh mutlak terhadap investasi mesin sebesar $100 \%$.

6. NPV dan IRR secara bersama-sama berperan terhadap keputusan investasi mesin pada CV. Seribu Wajah. Diperoleh hasil perhitungan NPV dan IRR keduanya memenuhi kriteria layaknya suatu investasi. Sehingga dinyatakan investasi mesin tersebut dinyatakan layak untuk dilakukan.

\section{Daftar Pustaka}

Abdune, J. (2013). Pengaruh domestic product, nilai tukar, suku bunga, dan inflasi terhadap penanaman modal asing di indonesia. Jurnal Airlangga university.

Baskara, Y. (2017). Pengaruh Faktor Fundamental Makro Ekonomi terhadap Keputusan Investasi Saham Asing di Indonesia tahun 2007-2014. Jurnal Administrasi Bisnis, Vol 47 No.1.

Dewi, P. K. (2015). Pengaruh pertumbuhan ekonomi, suku bunga dan pajak terhadap investasi asing langsung. Ejurnal Manajemen Unud, Vol 4 No 4, 866-878.

Eliza, M. (2013). Analisis pengaruh Makro Ekonomi terhadap Investasi Asing Langsung di Indonesia. Jurnal Malang. Fadilah, M. A. (2017). Analisis Produk Domestik Bruto, Suku bunga BI rate dan Inflasi terhadap Investasi Asing Langsung Tahun 2006-2015. Jurnal Jom Vekom, Vol 4 No.1.

Fahmi, I. (2011). Teori Portofolio dan Analisis Investasi. Bandung: Alfabeta.

Ginting. (2008). Pembangunan manusis di indonesia dan faktor-faktor yang mempengaruhinya. jurnal perencanaan \& pengembangan wilayah, Vol 4 No $1,113-122$.

Malik, A. (2017, Januari). Pengaruh utang luar negeri dan penanaman modal asing terhadap pertumbuhan ekonomi. Jurnal akuntansi, Vol 3 No 2.

Melinda, T. (2016). Pengaruh Pertumbungan Ekonomi, Bi rate dan Inflasi terhadap Investasi Asing Langsung di Indonesia. Jurnal Pendidikan Ekonomi, 4 No 3.

Rizalatul Isa, Ronny Malavia Mardani, \& Afi Rahmad Slamet. (2016). Pengaruh Tingkat Suku Bunga Deposito Bank Konvensional, Bagi Hasil, Likuiditas, PDB, terhadap Jumlah Penghimpunan Dana Pihak Ketiga Deposito Mudaharabah Bank Umum Syari'ah yang terdaftar di BI periode 20132016. Jurnal Riset Manangemen.

Rizky, R. L. (2016, Maret). Pengaruh penanaman modal asing, penanaman modal dalam negeri terhadap pertumbuhan ekonomi. jurnal JESP, Vol 8 No 1. 
Nunung Nurhayati dan Ayu Diah Restiani

Salim. (2008). Hukum Investasi di Indonesia. Jakarta: Grafindo.

Sarwedi. (2002). Investasi Asing Langsung di Indonesia dan Faktor yang mempengaruhinya. Jurnal Akuntansi dan Keuangan, 17-35.

Seftifany, A. T., Hidayat, R. R., \& Sulasmiyati, S. (2015, Agustus). Analisis Pengaruh Inflasi, Tingkat Suku Bunga, Nilai Tukar Rupiah dan Cadangan Devisa Terhadap Penanaman Modal Asing di Indonesia. Jurnal Administrasi Bisnis (JAB), Vol. 25 No. 2.

Soemitro, R. (2016). Dasar-dasar Hukum Pajak dan Pajak Pendapatan 1994. Bandung: PT. Eresco.
Sondakh, T. R. (2009). Implementasi Prinsip Trasparansi dalam Praktik Penanman modal di indonesia. Malang: Bayu media.

Sugiono. (2011). Metode penelitian pendidikan (pendekatan kuantitatif, kualitatif, dan R\&D. Bandung: Alfabeta.

Sukirno. (2011; 9). Ekonomi Pembangunan. Sutrisno, S. (2008). Hukum Investasi Di Indonesia. Jakarta: Grafindo Persada. Zaenuddin, m. (2009). Analisis FaktorFaktor yang mempengaruhi PMA di Batam. Jurnal Jejak, 156-166. 